\title{
The effect of pure argon and mixed gases on microstructural and mechanical properties of S275 structural steel joined by flux-cored arc welding
}

\author{
B. Çevik \\ Department of Welding Technology, Düzce University, 81850, Düzce, Turkey
}

Received 15 February 2017, received in revised form 21 June 2017, accepted 27 February 2018

\begin{abstract}
Studies on the use of various welding methods and equipment (electrode, welding wire, welding powder, etc.) in welding of steels have intensively continued nowadays. Flux-cored arc welding technology is one of the welding methods which have mostly been investigated and applied to different metals in recent years. In this study, the effect of different shielding gases on microstructural and mechanical properties of S275 structural steel joined by flux-cored arc welding was examined. Pure argon $(100 \% \mathrm{Ar})$ and a mixed gas $\left(86 \% \mathrm{Ar}, 12 \% \mathrm{CO}_{2}, 2 \%\right.$ $\mathrm{O}_{2}$ ) were used as shielding gas in welding processes. A double $\mathrm{V}$ groove of $50^{\circ}$ was opened on steel sheets. Welding processes were performed horizontally by using a $1.2 \mathrm{~mm}$-diameter rutile flux-cored wire. Tensile, hardness, and bending tests were used to determine mechanical properties of welded samples. In addition, metallographic examinations were performed to determine microstructural properties of weld zones. As a result of the tensile test, the highest mechanical properties were obtained from weld seams by the mixed gas. There were crack and rupture defects in weld zone as a result of bending tests. In all welding parameters, the hardness of weld metal was higher than that of the heat affected zone (HAZ) and base metal. The microstructure studies revealed that grain coarsening occurred in HAZ.
\end{abstract}

K e y w o r d s: flux-cored arc welding, shielding gas, argon, mixed gas, mechanical properties, microstructure

\section{Introduction}

The use of flux-cored wire electrode has a considerable share in arc welding methods performed under gas shielding [1]. Flux-cored arc welding (FCAW) method works with the same principle of gas metal arc welding (GMAW) method [1-3]. The difference between two techniques is that while GMAW method uses solid welding wires [3, 4], FCAW method uses flux-cored wires which contain slag-forming agent, gas-generating agent, alloying elements, and deoxidation elements $[1,5]$. These elements in the wire have the same function with coating of electrodes used in manual metal arc welding (MMAW) method [6]. In FCAW method, the heat required for welding is produced via arc formed between a melting and continuously fed wire electrode and workpiece and by heating the resistance of electrode due to welding current pass- ing through electrode. Welding wire is automatically fed to arc zone, melts, and generates welding metal [6-8]. In FCAW method, metal melt in weld zone is protected by an externally applied shielding gas (like GMAW) and a shielding gas atmosphere that occurs due to the composition of flux-core (like MMAW). When the arc occurs, these elements burn and generate welding smoke and also increase welding strength by alloying the weld metal [6-10].

Today, FCAW method has taken its part in the industry as both a production method and repair method. High welding speed, automatic applicability, high metal deposition rate, smooth welding seam, and easy applicability in all positions are important advantages of the method $[6,7]$. The use of flux-cored wire electrode has been increasing day by day especially because of high efficiency and easy application. The method is used in the production of the ship and

*Corresponding author: tel.: +90 380 7314005; fax: +90 380 7313124; e-mail address: bekircevik@duzce.edu.tr 
Table 1. Chemical composition of base metal and welding wire (wt.\%)

\begin{tabular}{lccccc}
\hline & $\mathrm{C}$ & $\mathrm{Si}$ & $\mathrm{Mn}$ & $\mathrm{P}$ & $\mathrm{S}$ \\
\hline S275 structural steel & 0.21 & 0.3 & 1.5 & 0.045 & 0.045 \\
Rutile flux-cored wire & 0.04 & 0.6 & 1.4 & 0.015 & 0.015 \\
\hline
\end{tabular}

marine structure, steel constructions (bridge, etc.), automobile and vehicle, boiler, storage equipment, and industrial machinery. Because thick section materials are used in marine structures, FCAW is preferred more since this method is fast, can be used in all positions, is easily applicable, and proper weld seams with high mechanical properties are obtained. The use of FCAW method has the highest application rate (approximately $60 \%$ ) especially in ships and marine vehicles. Thanks to its convenience in automation and by using with robots, its use in other industrial fields has been increasing each passing day $[1,6-8]$.

Shielding gas and/or mixed gases are chosen based on the type of welded metals. Chemical-metallurgical interaction of shielding gas, the weld metal melt during the welding, thermal conductivity capability of the gas, and the cost should be taken into account in choosing gas [11-14]. The primary function of shielding gases used in gas metal arc welding methods is to protect the melt weld metal from adverse effects of nitrogen and oxygen in the atmosphere $[6,11]$. Type and composition of the gas used are the most important factors in determining properties of the joined pieces. The composition of shielding gas determines the type of arc, the pattern of material transfer, and the amount of energy consumed on workpiece [11]. A good metal transfer, penetration, fusion width, welding geometry, welding rate, and low costs are expected from shielding gas. Another expectation is lack of formation of cracks and pores. Shielding gas also affects loss occurring due to spatters $[11,14]$. Different gas combinations are used in GMAW and FCAW methods. Pure argon (Ar), pure helium (He), and $\mathrm{CO}_{2}$ gases are used alone as a shielding gas, and also they are used as mixed. Moreover, different gas compositions $\left(\mathrm{Ar}-\mathrm{He}-\mathrm{CO}_{2}, \mathrm{Ar}-\mathrm{H}_{2}, \mathrm{Ar}-\mathrm{N}_{2}, \mathrm{Ar}-\mathrm{CO}_{2}, \mathrm{Ar}-\mathrm{CO}_{2}-\mathrm{O}_{2}\right.$, Ar- $\mathrm{CO}_{2}-\mathrm{N}_{2}$, and Ar- $\mathrm{He}$ ) are prepared by adding oxygen $\left(\mathrm{O}_{2}\right)$, hydrogen $\left(\mathrm{H}_{2}\right)$, and nitrogen $\left(\mathrm{N}_{2}\right)$ gases in various ratios and welding processes can be performed. Type and composition of the gas used affect metallurgical and mechanical properties of the joined material [6-14]. Several studies have been conducted about the effect of shielding gases used in FCAW method on mechanical and microstructural properties of the weld seam. Sathiya et al. [15] joined super austenitic stainless steel sheets with different gas combinations via $\mathrm{CO}_{2}$ laser-GMAW hybrid welding process. They stated that combination of shielding gas affected weld seam and tensile, hardness, and toughness properties. They reported that they obtained better mechanical properties by $50 \% \mathrm{He}+45 \% \mathrm{Ar}+5 \% \mathrm{O}_{2}$ gas mixture. Katherasan et al. [16] joined AISI 316L austenitic stainless steel sheets by using FCAW method and different gas combinations. They stated that the combination of shielding gas was effective on their mechanical and microstructural properties. They reported that optimal mechanical and microstructural properties were obtained in pure Ar gas. Liao and Chen [17] joined AISI 304 stainless steel sheets with different gas combinations by GMAW and FCAW methods. They reported that optimal mechanical properties were obtained in the combination of $98 \% \mathrm{Ar}+2 \% \mathrm{CO}_{2}$ gas. The number of studies on the effect of choosing shielding gas on mechanical and metallurgical properties of weld zone in joining of different types of steels by GMAW and FCAW methods has intensely been increasing.

In this study, the effect of different shielding gases on microstructural and mechanical properties of S275 structural steel joined by flux-cored arc welding method was investigated. S275 structural steels are commonly used especially in steel constructions. Tensile, hardness, and bending tests were applied to determine the effect of shielding gas type on mechanical properties of welded joints. Furthermore, microstructures occurring in the heat affected zone and weld metal, as well as grain morphology, were evaluated.

\section{Material and method}

In this study, S275 structural steel sheets in sizes of $200 \times 80 \times 10 \mathrm{~mm}^{3}$ were joined by using FCAW method. Table 1 shows chemical compositions of S275 structural steel and welding wire, Table 2 shows their mechanical properties, and Fig. 1 shows microstructure of the base metal. The microstructure of the base metal had a coaxial ferrite and pearlite structure.

As in Fig. 2, a double $\mathrm{V}$ groove of $50^{\circ}$ was opened on steel sheets, and the sheets were centered by leaving $1.2 \mathrm{~mm}$ between them. Pure argon gas (100\% Ar) and mixed gas ( $\mathrm{Ar} 86 \%, \mathrm{CO}_{2} 12 \%, \mathrm{O}_{2} 2 \%$ ) were used as shielding gas in welding processes. A $1.2 \mathrm{~mm}$ diameter rutile flux-cored wire (EN ISO 17632-A) was used as welding wire. Rutile flux-cored welding wire can be commonly used in welding of machinery and ship constructions in every position. GKM 420-2W type, water cooled gas metal arc welding machine was used for welding processes. Welding processes were performed in a horizontal position by using the welding parame- 
Table 2. Mechanical properties of base metal and welding wire

\begin{tabular}{lccc}
\hline & $\begin{array}{c}\text { Yield strength } \\
(\mathrm{MPa})\end{array}$ & $\begin{array}{c}\text { Tensile strength } \\
(\mathrm{MPa})\end{array}$ & $\begin{array}{c}\text { Elongation } \\
(\%)\end{array}$ \\
\hline S275 structural steel & $\min .245$ & 612.5 & 34 \\
Rutile flux-cored wire & 420 & $500-640$ & min. 22 \\
\hline
\end{tabular}

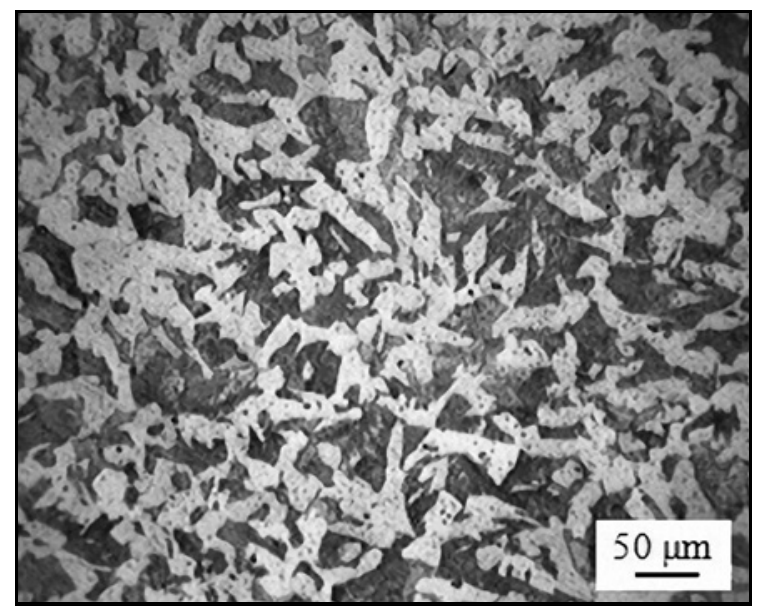

Fig. 1. Microstructure of the base metal.

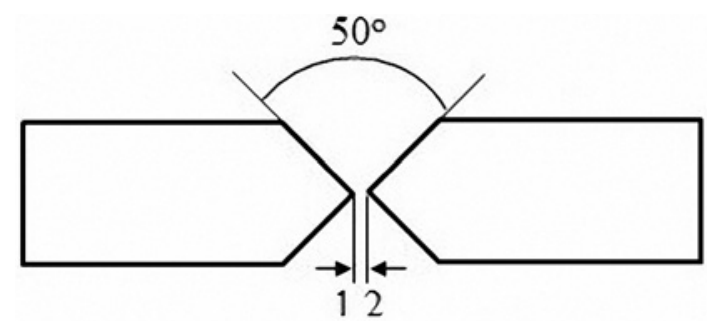

Fig. 2. Weld groove configuration.

Table 3. Welding parameters

\begin{tabular}{ll}
\hline Welding current & $150 \mathrm{~A}$ \\
Welding voltage & $24 \mathrm{~V}$ \\
Wire speed & $5 \mathrm{~m} \mathrm{~min}^{-1}$ \\
Welding speed & $5 \mathrm{~mm} \mathrm{~s}^{-1}$ \\
Gas flow rate & $12 \mathrm{lmin}^{-1}$ \\
Electrode diameter & $1.2 \mathrm{~mm}$ \\
Shielding gas & $\mathrm{Ar} 100 \%$ \\
& $\mathrm{Ar} 86 \%, \mathrm{CO}_{2} 12 \%, \mathrm{O}_{2} 2 \%$ \\
\hline
\end{tabular}

ters in Table 3. Welding parameters used in the studies were chosen as a result of preliminary studies. The samples with completed welding process were left for cooling at outdoor.

In addition to metallographic tests, the joined sam-

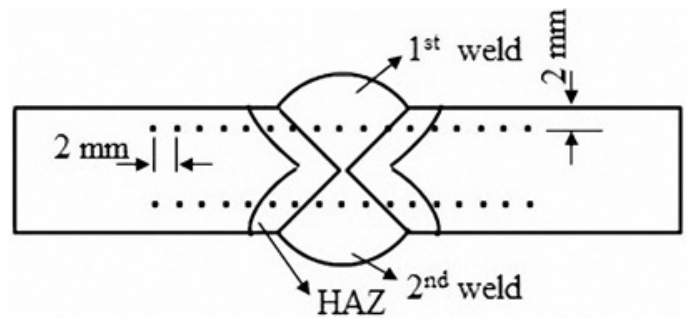

Fig. 3. Hardness distribution plan.

ples were also subjected to mechanical tests such as hardness, tensile, and bending tests. 3 samples for tensile test, 3 samples for bending test, and 1 sample for microstructure and hardness test were prepared from welded samples. The samples for the tensile test were prepared according to ASTM-E8 standard. The samples for bending test were produced according to TS EN ISO 5173 standard. Tensile tests were performed by using BME-T series $100 \mathrm{kN}$ universal tensile test device. Fracture surface analyses of the samples were performed by using FEI Quanta FEG 250 brand scanning electron microscope (SEM). The three-point bending tests were performed by using $50 \mathrm{kN}$ Instron 3369 tensile/bending test device at $10 \mathrm{~mm} \mathrm{~min}^{-1}$ test speed and $60 \mathrm{~mm}$ support opening. The microstructure and hardness of the samples were subjected to sanding, polishing, and etching processes through standard methods. The samples were etched with $2 \%$ nital solution and examined by using Metkon inverted metal microscope. Hardness distribution of the welded samples was determined in Rockwell B $\left(\mathrm{HR}_{\mathrm{B}}\right)$ by using universal hardness test device. Hardness processes were performed on 17 points with $2-\mathrm{mm}$ interval for $10 \mathrm{~s}$ by applying $100 \mathrm{kgf}$ load via $1 / 16$ " steel ball (Fig. 3).

\section{Results and discussion}

\subsection{Tensile test results}

Table 4 shows tensile test results of the samples welded through flux-cored arc welding method using different shielding gases. Welding efficiency of the welded joints was calculated by using the formula:

$$
\% \mathrm{WE}=(\mathrm{SW} / \mathrm{SBM}) \times 100
$$


Ta b le 4. Results of tensile test

\begin{tabular}{lccc}
\hline & Tensile strength & Elongation & \multicolumn{2}{c}{ Welding efficiency } \\
& $(\mathrm{MPa})$ & $(\%)$ & - \\
\hline S275 steel (base metal) & 612.5 & 34 & 78.6 \\
Pure Ar & 481.4 & 23.9 & 96.2 \\
Mixed gas (Ar 86\%, $\left.\mathrm{CO}_{2} 12 \%, \mathrm{O}_{2} 2 \%\right)$ & 589.8 & 30.7 & \\
\hline
\end{tabular}

where WE is welding efficiency, SW is the strength of welding, and SBM is the strength of the base metal. As tensile test results were examined, it was observed that the base metal had the highest tensile strength and $\%$ elongation. As a result of the tensile test, it was determined that tensile strength of the base metal was $612.5 \mathrm{MPa}$ and \% elongation was $34 \%$. When tensile test results of the welded joints were compared, the highest tensile strength was obtained from samples welded by mixed gas. Tensile strength of $589.8 \mathrm{MPa}$ was determined in the joint welded by mixed gas. There was a decrease of $3.8 \%$ in tensile strength compared to the base metal. \% elongation ratio of the sample welded by mixed gas was $30.7 \%$ and a decrease of $9.7 \%$ was observed compared to $\%$ elongation value of base metal. Kilinçer and Kahraman [14] stated that the first condition required for welding process is that strength of the joint needs to be the same or close to that of a base material. Therefore, this condition was approximately observed in joints welded by mixed gas. $\mathrm{CO}_{2}$ gas of $12 \%$ added to Ar gas increased tensile strength. The tensile strength of the joint performed by using pure Ar gas was 481.4 MPa. When tensile strength of this sample was compared with base metal, it decreased at the rate of $21.4 \% . \%$ elongation value of the sample joined by using pure Ar was $23.9 \%$, and a decrease of $29.7 \%$ was observed compared to \% elongation value of the base metal. Figure 4 shows the fracture behavior of the samples. The base metal displayed a ductile fracture behavior and had large cavities on the fracture surface. When fracture surface behavior of the welded samples was examined, it was observed that there were microvoid defects. Even though the welded samples displayed a ductile fracture behavior, finer cavities occurred compared to base metal.

\subsection{Three-point bending test results}

The bending test was applied to the welded samples in accordance with the standards. Maximum bending stresses were determined as a result of bending tests. Table 5 shows bending test results of the base metal and the samples welded by flux-cored arc welding method using different shielding gases. As a result of the bending test, it was observed that there were fractures in all welded samples. When bending test results were examined, it was found that the base metal had the highest bending strength (1247.1 MPa).
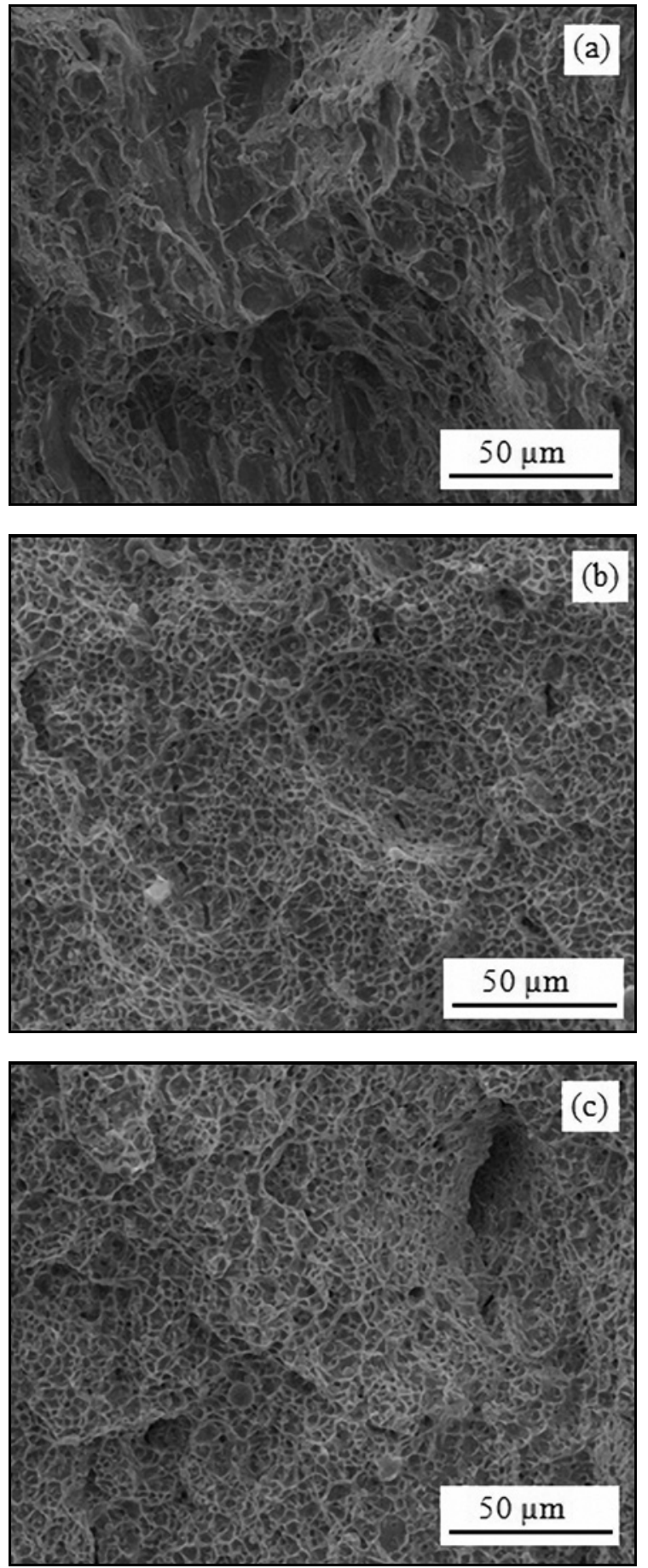

Fig. 4. Fracture behavior of samples: (a) base metal, (b) pure Ar gas, and (c) mixed gas. 
Table 5. Results of bending test

\begin{tabular}{lcc}
\hline & Max. bending stress (MPa) & Bending behavior \\
\hline S275 steel (base metal) & 1247.1 & \\
Pure Ar & 884.5 & \\
Mixed gas (Ar $\left.86 \%, \mathrm{CO}_{2} 12 \%, \mathrm{O}_{2} 2 \%\right)$ & 1062.6 & \\
\hline
\end{tabular}
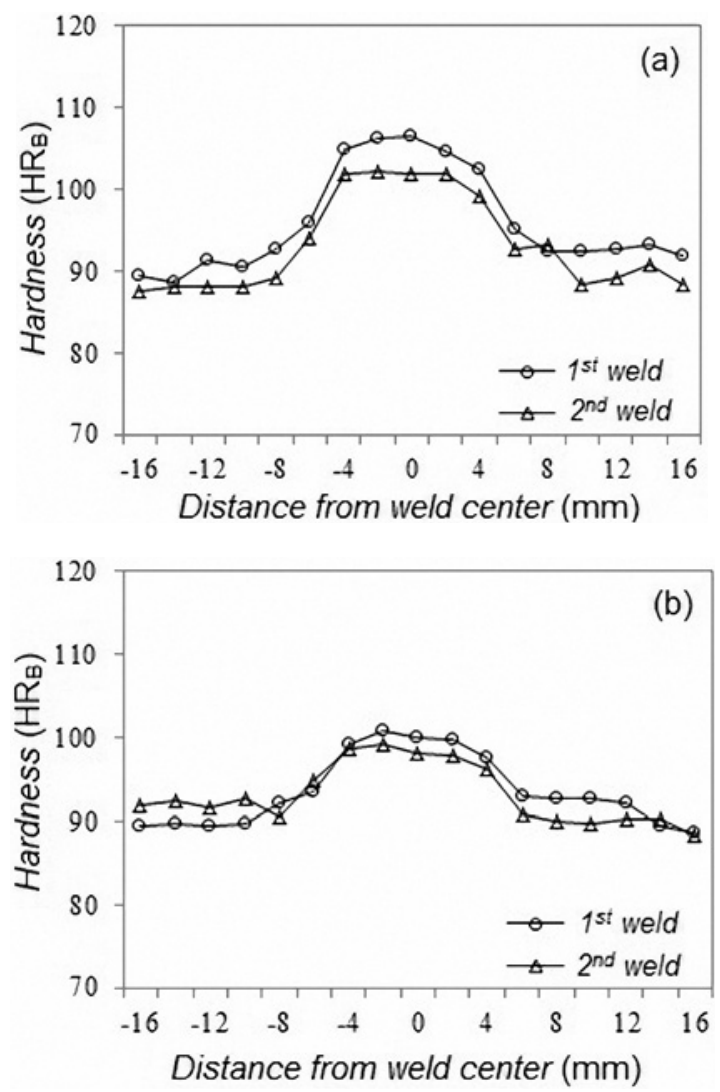

Fig. 5. Hardness distribution of welded samples: (a) pure Ar gas, (b) mixed gas.

Bending strength of the joint welded by using pure Ar was $884.5 \mathrm{MPa}$. Bending strength of this sample decreased at the rate of $29 \%$ compared to base metal. Bending strength of the joint welded by mixed gas was $1062.6 \mathrm{MPa}$, and there was a decrease of $14.7 \%$ in its bending strength compared to the base metal.
$\mathrm{CO}_{2}$ gas of $12 \%$ added to Ar gas during welding process increased bending strength slightly compared to the samples welded by using pure Ar gas. However, microvoid defects and porosities occurring in weld seam during solidification decreased bending strength of welded samples.

\subsection{Hardness results}

Figure 5 shows hardness distribution of the weld zone (base metal, HAZ, weld metal) in the samples joined by using pure Ar and mixed gas. The highest hardness values of the welded samples were measured in weld metals, which was followed respectively by HAZ and base metal. Mean hardness value of the base metal was $\sim 84 \mathrm{HR}_{\mathrm{B}}$. Hardness values of welding center of the sample joined by using pure argon gas were higher compared to the sample joined by mixed gas. This was associated with a lower heat input in weld zone with argon gas. While hardness values of weld metal of the sample joined under pure Ar gas atmosphere were $102-106 \mathrm{HR}_{\mathrm{B}}$, a hardness value of HAZ was in the range of $92-104 \mathrm{HR}_{\mathrm{B}}$. While hardness values of weld metal of the sample joined under mixed gas atmosphere were in the range of $98-101 \mathrm{HR}_{\mathrm{B}}$, a hardness value of HAZ was in the range of 89-98 $\mathrm{HR}_{\mathrm{B}}$. Graphs in Fig. 5 show that close hardness values were obtained in the first and second weld seams. Sönmez and Ceyhun [1] reported that hardness values measured in different zones were close to each other, which was associated with choosing interpass temperature and welding parameters properly and keeping them under control. In the literature [18], it is recommended that hardness should not exceed $350 \mathrm{HV}$ $\left(\sim 109 \mathrm{HR}_{\mathrm{B}}\right)$ as a precaution against cracking in HAZ in welding low carbon low alloy steels. Because hardness distributions of the welded samples are below this 

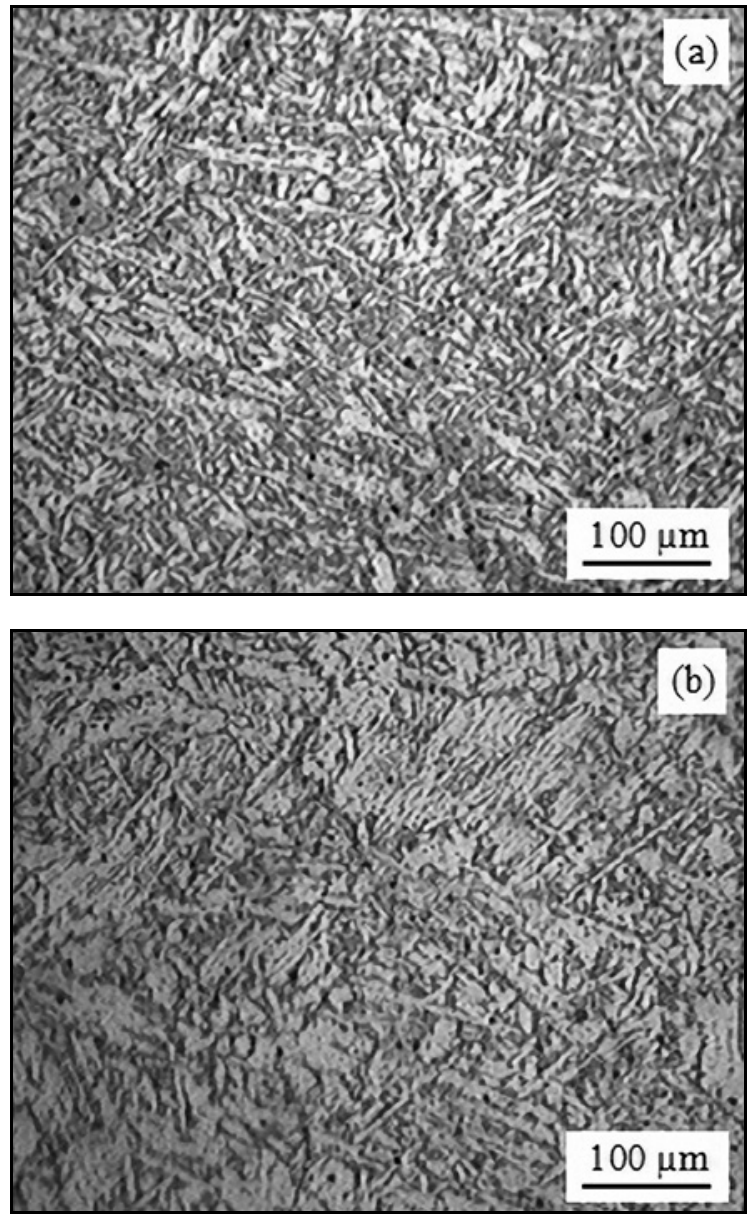

Fig. 6. Microstructure of weld metal: (a) pure Ar gas, (b) mixed gas.

critical value, there is no need for post-welding heat treatment. Kaya et al. [18] stated that the hardest zone was the weld metal in steels welded with a carbon ratio less than $0.22 \%$ by using arc welding, and hardness values decreased from the weld metal to the base metal.

\subsection{Microstructural examination}

An easy arc ignition was ensured, a stable arc was formed, and when pure Ar gas was used, a nospatter welding seam was obtained. When a $\mathrm{CO}_{2}$ gas of $12 \%$ was added to Ar gas, the amount of spatters increased. Type and composition of shielding gas are the most important factors in determining properties of the joined pieces. In addition to its effect on mechanical properties and microstructure of weld seam, the composition of shielding gas also is effective on losses caused by spatters during the welding process. Weld zone needs to be cleaned because of spatters. In this condition, it causes waste of time, energy and financial losses $[11,12]$. Liao and Chen [19] investigated
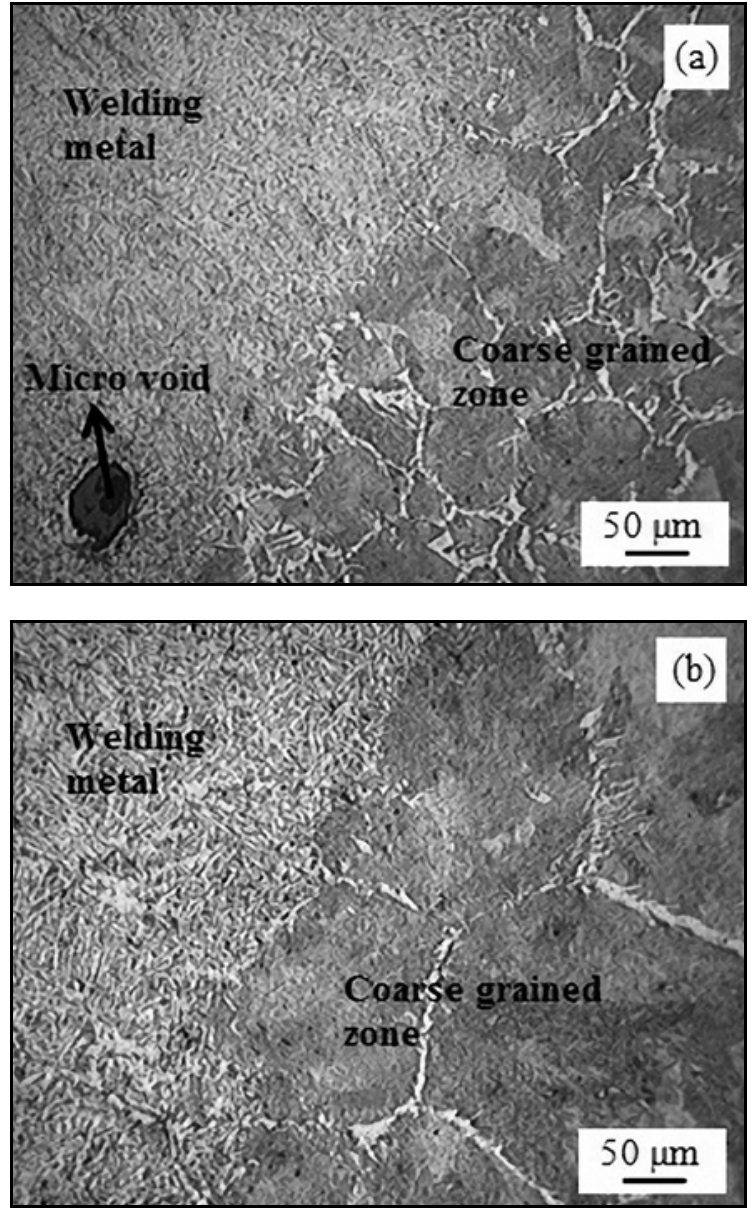

Fig. 7. Microstructure of transition zone in welded samples: (a) pure Ar gas, (b) mixed gas.

the effects of $\mathrm{CO}_{2}$ in various amounts added into argon gas used as shielding gas in MIG welding method on spatter ratios and microstructural and mechanical properties. They determined that the amount of spatters increased with the increase of $\mathrm{CO}_{2}$ in argon and size of spattering pieces also increased with the increasing carbon $(\mathrm{C})$ ratio.

Figure 6 shows microstructures of weld metal of the S275 structural steel joined by flux cored arc welding using pure Ar and mixed gas. The microstructure of both weld metals consisted of thin acicular grains. However, weld metal sample welded by pure Ar gas had finer grain structure compared to the sample joined by mixed gas (Fig. 6a). This was associated with the fact that pure Ar gas caused lower heat input during the welding process. $12 \%$ of $\mathrm{CO}_{2}$ gas added to Ar increased heat input and melting capacity and caused grain size of weld metal to grow (Fig. 6b). In the literature $[1,14,20]$, it is reported that structures formed in low carbon low alloy weld metal depending on cooling rate are likely grain boundary ferrite, Widmanstätten ferrite, acicular ferrite, bainite, and per- 
lite. As microstructures of weld metal were examined, it was observed that mainly grains of Widmanstätten ferrite and acicular ferrite (acicular parts) formed.

Figure 7 shows microstructures of the transition zone of welded samples. In both joining processes, weld metals, HAZs, and zones adjacent to weld melting boundary generated similar views. However, the grain size of HAZ in joint welded by mixed gas was observed to have larger grains compared to joint welded by pure Ar gas. $30-60 \mu \mathrm{m}$ sized micro grains formed in the coarse-grained zone of joint welded by pure Ar gas (Fig. 7a). In addition, microvoids were observed in the weld metal and parts that are close to the transition zone of joint welded by pure Ar gas. In the joint welded by using mixed gas, on the other hand, grain sizes in the coarse-grained zone were 120-200 $\mu \mathrm{m}$ (Fig. 7b). Mixed gas caused higher heat input and larger grains in the coarse-grained zone. Kaya et al. [18] stated that coarse columnar grains formed in the zones closest to weld metal due to the effect of heat input in arc welding metals.

\section{Conclusions}

S275 structural steel sheets were joined under pure Ar gas and mixed gas atmospheres by using rutile fluxcored wire in flux-cored arc welding method, and microstructural and mechanical properties of the welded joints were examined. The results are summarized below:

1. S275 structural steel sheets were successfully joined under pure Ar gas and mixed gas atmospheres by using rutile flux-cored wire by using flux-cored arc welding method.

2. Shielding gas was effective on mechanical and microstructural properties of steels welded by using flux-cored arc welding method.

3. More coarse grains formed in both weld metal and HAZ in joint welded by using mixed gas.

4. The hardness of weld metal was higher than that of HAZ and base metal in joints welded by both shielding gases.

5. As a result of the tensile test, the highest strength was obtained for samples welded by mixed gas close to base metal. Moreover, fracture of all welded joints occurred close to transition zone between weld metal and coarse-grained zone.

6. As a result of bending test, the highest bending strength was obtained for samples welded by using mixed gas close to base metal.

\section{References}

[1] Sönmez, U., Ceyhun, V.: Kovove Materialy-Metallic Materials, 52, 2014, p. 57. doi:10.4149/km_2014_1_57

[2] Absi Alfaro, S. C., Carvalho, G. C., de Menlo Júnior, S. A.: Journal of Materials Processing Technology, 157, 2004, p. 3. doi:10.1016/i.jmatprotec.2004.09.002

[3] Kaçar, R., Kökemli, K.: Materials \& Design, 26, 2005, p. 508. doi:10.1016/i.matdes.2004.07.027

[4] Suban, M., Tusek, J.: Journal of Materials Processing Technology, 119, 2001, p. 185. doi:10.1016/S0924-0136(01)00940-2

[5] Ghazvinlo, H. R., Honarbakhsh Raouf, A.: Journal of Applied Science, 10, 2010, p. 658, 2010. doi:10.3923/jas.2010.658.663

[6] Eryürek, İ. B.: Gas Metal Arc (MIG/MAG) Welding. Istanbul, Askaynak 1998.

[7] Morimoto, T.: Kobelco Technology Review, 26, 2005, p. 49.

[8] Ceyhun, V., Elove, D., Tatlises, B., Tunca, I.: Metal World, 169, 2007, p. 116.

[9] Karadeniz, E., Ozsarac, U., Yildiz, C.: Materials \& Design, 28, 2007, p. 649. doi:10.1016/j.matdes.2005.07.014

[10] Durgutlu, A.: Materials \& Design, 25, 2004, p. 19. doi:10.1016/j.matdes.2003.07.004

[11] Yilmaz, R., Barlas, Z.: Pamukkale University Journal of Engineering Sciences, 11, 2005, p. 391.

[12] Gülenç, B., Develi, K., Kahraman, N., Durgutlu, A.: International Journal of Hydrogen Energy, 30, 2005, p. 1475. doi:10.1016/j.ijhydene.2004.12.012

[13] Aloraier, A., Ibrahim, R., Thomson, P.: International Journal of Pressure Vessels and Piping, 83, 2006, p. 394. doi:10.1016/j.ijpvp.2006.02.028

[14] Kilinçer, S., Kahraman, N.: Journal of the Faculty of Engineering and Architecture of Gazi University, 24, 2009, p. 23.

[15] Sathiya, P., Mishra, M. K., Shanmugarajan, B.: Materials \& Design, 33, 2012, p. 203. doi:10.1016/j.matdes.2011.06.065

[16] Katherasan, D., Sathiya, P., Raja, A.: Materials \& Design, 45, 2013, p. 43. doi:10.1016/i.matdes.2012.09.012

[17] Liao, M. T., Chen, W. J.: The International Journal of Advanced Manufacturing Technology, 15, 1999, p. 49. doi: $10.1007 / \mathrm{s} 001700050038$

[18] Kaya, Y., Kahraman, N., Durgutlu, A., Gülenç, B.: eJournal of New World Science Academy, 5, 2010, p. 348.

[19] Liao, M. T., Chen, W. J.: Materials Chemistry and Physics, 55, 1998, p. 145. doi:10.1016/S0254-0584(98)00134-5

[20] Akay, A. A., Kaya, Y., Kahraman, N.: Sakarya University Journal of Science, 17, 2013, p. 85. 